\title{
An international review of the patterns and determinants of health service utilisation by adult cancer survivors
}

\author{
Charlene Treanor ${ }^{* *}$ and Michael Donnelly ${ }^{1,2}$
}

\begin{abstract}
Background: There is a need to review factors related to health service utilisation by the increasing number of cancer survivors in order to inform care planning and the organisation and delivery of services.

Methods: Studies were identified via systematic searches of Medline, PsycINFO, CINAHL, Social Science Citation Index and the SEER-MEDICARE library. Methodological quality was assessed using STROBE; and the Andersen Behavioural Model was used as a framework to structure, organise and analyse the results of the review.

Results: Younger, white cancer survivors were most likely to receive follow-up screening, preventive care, visit their physician, utilise professional mental health services and least likely to be hospitalised. Utilisation rates of other health professionals such as physiotherapists were low. Only studies of health service use conducted in the USA investigated the role of type of health insurance and ethnicity. There appeared to be disparate service use among US samples in terms of ethnicity and socio-demographic status, regardless of type of health insurance provision s- this may be explained by underlying differences in health-seeking behaviours. Overall, use of follow-up care appeared to be lower than expected and barriers existed for particular groups of cancer survivors.

Conclusions: Studies focussed on the use of a specific type of service rather than adopting a whole-system approach and future health services research should address this shortcoming. Overall, there is a need to improve access to care for all cancer survivors. Studies were predominantly US-based focussing mainly on breast or colorectal cancer. Thus, the generalisability of findings to other health-care systems and cancer sites is unclear. The Andersen Behavioural Model provided an appropriate framework for studying and understanding health service use among cancer survivors. The active involvement of physicians and use of personalised care plans are required in order to ensure that post-treatment needs and recommendations for care are met.
\end{abstract}

Keywords: Cancer survivor, Health service utilisation, Systematic review, Andersen Behavioural Model

\section{Background}

The number of cancer survivors (CSs) is increasing steadily due to several factors including improved medical treatment and an aging population [1]. However, there are relatively few studies about health service use by individuals with this chronic condition. The few studies that have been conducted in this field provide mixed results about the nature and extent to which CSs have poorer health and a greater need for services than

\footnotetext{
* Correspondence: ctreanor05@qub.ac.uk

${ }^{1}$ Cancer Epidemiology \& Health Services Research Group, Centre for Public Health, Queen's University Belfast, Belfast, UK

Full list of author information is available at the end of the article
}

primary care patients and other chronic disease groups $[2,3]$. There is a need to investigate health service utilisation in order to understand access to services, identify any service gaps and to improve organisational efficiency and cost-effectiveness [4]. The nature and type of services required by the CS population including effective and efficient ways in which to organise, deliver and facilitate services is relatively unexamined. The purpose of this paper is to present the results of a systematic review of the literature related to the patterns and determinants of the use of preventive health care services, hospital care and primary care by cancer survivors.

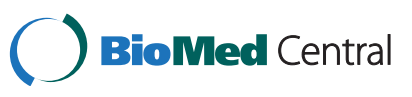




\section{Methods}

MEDLINE, CINAHL, PsycINFO, Social Science Citation Index and the SEER-MEDICARE online library of publications were searched from 1950 to August 2011. The search terms revolved around the key concepts: cancer survivors and health service utilisation (see Figure 1). The methodology adhered to guidelines by the Centre for Review and Dissemination [5]. Independent study selection was undertaken by two reviewers who achieved $98 \%$ agreement. Data were extracted using a prespecified pro-forma.

Papers published in peer-review journals were included if participants were diagnosed with cancer in adulthood; had completed active treatment with curative intent and were not in receipt of palliative care. Nonmelanoma skin CSs were excluded as both treatment and survival differ from other cancer sites [6]. The review included studies of key formal service components including primary care, hospital services, social services, mental health services (and their costs). Studies of eHealth systems, lay-led supportive services, dentistry and complementary and alternative medicine were excluded. Many CSs use these other types of services, particularly complementary and alternative therapies in order to manage the long-term morbidity associated with cancer. However, these service types were excluded from the review due to resource limitations and each service type would warrant a separate review.

The STrengthening the Reporting of OBservational studies in Epidemiology (STROBE) checklist was supplemented with a survey appraisal checklist in order to appraise the methodological quality of the full range of study types $[7,8]$.

The Andersen Behavioural Model provided the theoretical and organisational framework for the review and synthesis of studies. Service use by CSs was explained in terms of three main components: characteristics which predispose (e.g. age, sex and health beliefs) an individual to use health care; enabling characteristics (e.g. resources)

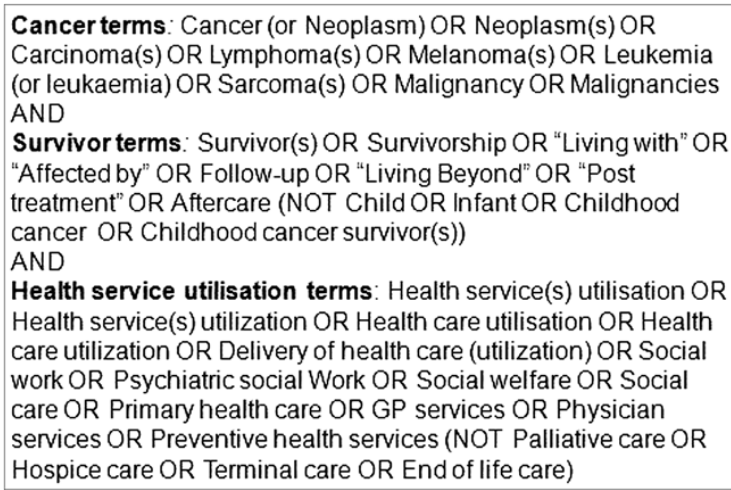

Figure 1 Full search strategy. that facilitate access to health care; and need in the form of an illness or symptoms that require care (e.g. follow-up screening to detect cancer recurrence or metastases). This model was used as the organisational framework because it was developed as an explanatory framework explicitly for health service utilisation; it has been applied across various types of health services and health care systems and there is a large associated international literature on its performance. It encompasses individual characteristics and takes into consideration the context in which health care occurs.

\section{Results}

\section{Study characteristics}

A total of 38 studies were included in the review (see Figure 2); studies took place in the USA (27), UK (3), Netherlands (3), Canada (3), France (1) and Denmark (1). Breast CSs were the population of interest in the majority of studies (18); other studies comprised colorectal CSs (11), uterine CSs (1) or survivors from a number of cancer sites (7). See Tables 1 and 2 for study characteristics. The country of study origin is stated in the results below unless studies were conducted in the USA. Studies focussed on primary care (26), post-active treatment cancer surveillance (15), preventive care, e.g. influenza vaccination, (8), mental health service use, e.g. psychologists, (3) and hospital care, including inpatient and outpatient services (2). Use of social services was not a primary focus of any of the identified papers. The studies investigated the prediction of service utilisation but not the nature and extent of service integration and coordination. Quality appraisal scores ranged from 11 to 20, $($ mean $=17)$, indicating that the majority of studies $(n=25)$ were very good quality. No study exclusions were made based on quality.

\section{Primary care \\ Predisposing characteristics}

The US health-care system permits individuals to choose to an extent which health care provider provides their care in relation to their insurance plan restrictions or absence of an insurance plan. Specialists are included in this section on primary care as data indicated that there is a limited set of services used by patients in the US health care system that may be provided by a specialist such as an oncologist or by a primary care physician. There was a consistent association between contact with primary care and predisposing characteristics such as age, ethnicity, gender and time since diagnosis. Contact with services for cancer-related problems and all symptoms and illnesses are included within the results. Studies were inconsistent regarding whether younger or older CSs were more likely to visit an oncologist or a primary care physician. Younger colorectal CSs were 


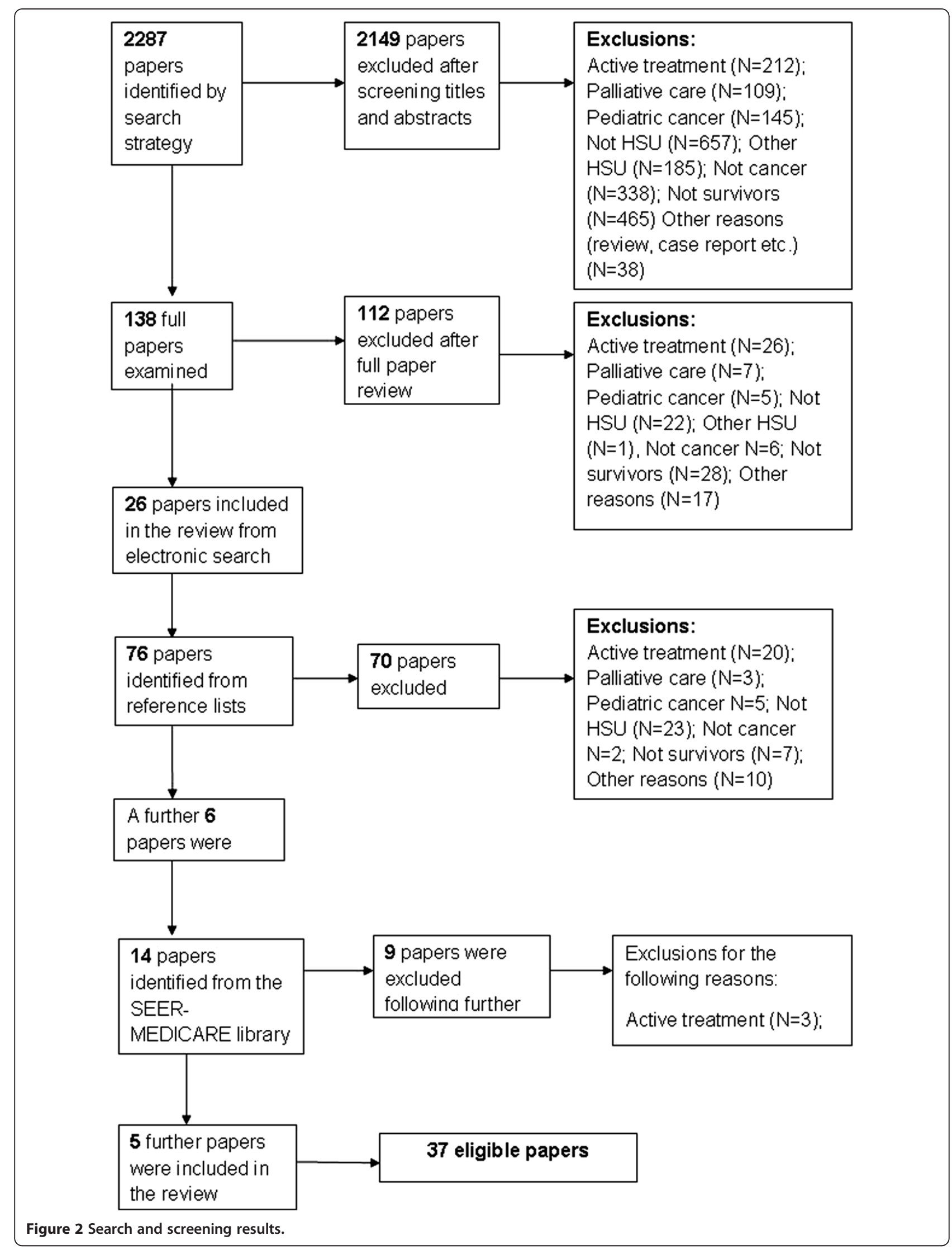


more likely to visit both a primary care physician and an oncologist, whereas older colorectal CSs were more likely to visit only a primary care physician $[9,10]$. Moreover, younger breast CSs from the US were more likely to visit an oncologist [11], whereas older breast CSs from Denmark were most likely to visit their primary care physician [12]. Differences in the pattern of primary care utilisation by ethnicity were found across cancer sites. Black colorectal CSs were more likely to receive care from physicians other than a primary care physician, whereas, white colorectal CSs were more likely to receive care from a primary care physician [10]. Furthermore, white breast CSs were more likely to utilise health services compared to black CSs [13]. Compared to male colorectal CSs, female colorectal CSs were more likely to receive care from a primary care physician and an oncologist than either one of these physicians only [9]. Only one study (conducted in the Netherlands) addressed time since diagnosis and the use of primary care services. Dutch endometrial CSs diagnosed between 10 and 15 years previously were less likely to visit a primary care physician than CSs diagnosed within 10 years or very long-term survivors at least 15 years post-diagnosis [14].

\section{Enabling characteristics}

Area of residence, participation in an intervention, primary care physician-orientated follow-up and marital status (as a proxy for social support) acted as significant enablers for primary care service use. French colorectal CSs from the Saône and Loire regions were more likely to have made regular contact with a primary care physician than CSs from other French regions [15]. One UK study demonstrated that the orientation of follow-up cancer care was important for health service use. CSs who received hospital-oriented follow-up had lower health-care utilisation rates compared to CSs whose follow-up care was oriented by their primary care physician [16]. A small proportion of Canadian breast cancer survivors whose follow-up care was provided by a primary care provider made visits to an oncologist over a 12 month period [17]. A reduction in health service use was observed for breast CSs who participated in a psychotherapy-based intervention to reduce stress [18]. One study from the Netherlands found that a lack of social support (i.e. CSs who were single or divorced) led to less use of health services compared to CSs who were married [14].

\section{Need characteristics}

A number of studies found that co-morbidities were associated with visits to primary care. Breast CSs with a co-morbidity, or self-reported poor functioning or high depressive mood had greater service utilisation and health-care costs than breast CSs without a co-morbidity, or who reported better functioning or had low scores low depressive mood [13]. Similarly in the Netherlands health service utilisation rates were two times greater for cancer survivors with a co-morbidity compared to CSs without a co-morbidity [14]. It is not clear from the findings whether CSs were more or less likely to utilise primary care services compared to a non-cancer control population. Compared to individuals without cancer, US and UK colorectal CSs, UK prostate CSs and Dutch endometrial survivors $[14,19,20]$, were significantly more likely to visit their primary care physician. However, Dutch CSs and Danish breast CSs had similar primary care physician use as non-cancer controls [12,21,22]. In terms of the level of contact made with primary care patterns of utilisation changed over time. Contact with oncologists largely decreased over time, whereas visits to a primary care physician largely increased over time. Annual visits to primary care physicians and oncologists were made by $51 \%$ and $27 \%$ of breast CSs respectively [11]. Within the first year of survivorship there was a high health service utilisation rate for breast CSs; an average of 14 visits per individual was made to a medical provider including a primary care physician or an oncologist [13]. Approximately $50 \%$ of CSs visited an oncologist alongside other physicians, whereas $8 \%$ of CSs made visits to only an oncologist [19]. One crosssectional study reported that $52 \%$ of breast CSs made visits to both an oncologist and a primary care physician, whereas $41 \%$ visited a primary care physician only and $4 \%$ visited an oncologist only [23]. The level of contact made to both primary care physicians and oncologists decreased over a three year period, from 70-42\% and 30-17 \%, respectively. One longitudinal study found that in the first year of follow-up, the majority of breast CSs made visits to both physicians; over time the number of visits made to a primary care physician decreased and the number of visits made to an oncologist increased [24]. In contrast, further studies reported an increase in the number of visits to a primary care physician and a decrease of visits to an oncologist and other physicians over time for colorectal and breast CSs respectively $[9,10,13,20,25-27]$.

\section{Follow-up cancer surveillance Predisposing characteristics}

Follow-up cancer surveillance includes any test which is used to screen for recurrence or metastases of the primary cancer. Each study which addressed the predisposing characteristics associated with CSs who utilised follow-up cancer surveillance procedures was conducted in the USA. Predisposing characteristics found to be significantly related to follow-up cancer surveillance were age, ethnicity, gender and health beliefs. Older age was associated with receipt of less follow-up cancer surveillance procedures. Compared to their younger counterparts, older 
Table 1 Study Characteristics

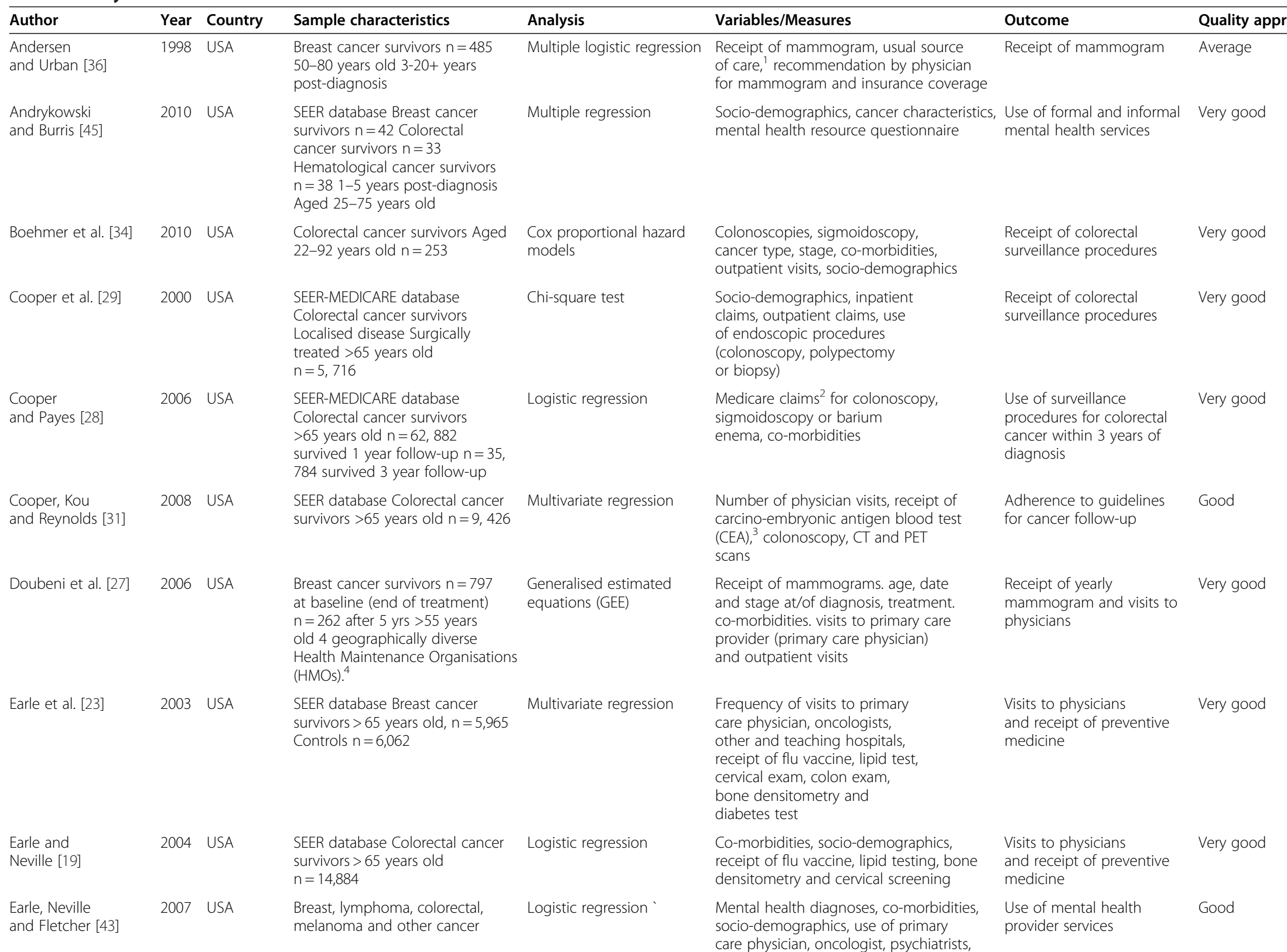


Table 1 Study Characteristics (Continued)

\begin{tabular}{|c|c|c|c|c|c|c|c|}
\hline & & & $\begin{array}{l}\text { survivors Mean age } 60 \text { years } \\
n=1,111 \text { Controls } n=4,444\end{array}$ & & $\begin{array}{l}\text { psychologists, social workers and } \\
\text { inpatient hospitalisations (both general } \\
\text { and mental). }\end{array}$ & & \\
\hline Ellison et al. [33] & 2003 & USA & $\begin{array}{l}\text { SEER database Colorectal cancer } \\
\text { survivors }>65 \text { years old } \\
n=52,105\end{array}$ & $\begin{array}{l}\text { Kaplan-Meier survival } \\
\text { analysis Unconditional } \\
\text { regression analysis } \\
\text { Cox regression }\end{array}$ & $\begin{array}{l}\text { Socio-demographic, hospital and } \\
\text { clinical characteristics, receipt of } \\
\text { colonoscopy, sigmoidoscopy, } \\
\text { endoscopy and barium enema }\end{array}$ & $\begin{array}{l}\text { Differential receipt of } \\
\text { colonoscopy, } \\
\text { sigmoidoscopy, } \\
\text { endoscopy and barium } \\
\text { enema by race }\end{array}$ & Good \\
\hline Gray et al. [41] & 2000 & Canada & $\begin{array}{l}\text { Breast cancer survivors } n=731 \\
\text { Histologically confirmed and } \\
\text { invasive }\end{array}$ & Stepwise logistic regression & $\begin{array}{l}\text { Use of specialised supportive } \\
\text { care services, wish to use services that } \\
\text { were not accessed, social and } \\
\text { demographic characteristics. }\end{array}$ & $\begin{array}{l}\text { Use of professional } \\
\text { supportive care services } \\
\text { provided by the Ontario } \\
\text { health care system }\end{array}$ & Very good \\
\hline Gray et al. [42] & 2002 & Canada & $\begin{array}{l}\text { Breast cancer survivors } 63 \% \\
<60 \text { years old } 23-36 \text { months } \\
\text { post-diagnosis } n=731\end{array}$ & Logistic regression & $\begin{array}{l}\text { Supportive care from physicians and } \\
\text { nurses, socio-demographics, } \\
\text { illness and treatment } \\
\text { information }\end{array}$ & $\begin{array}{l}\text { Use of professional } \\
\text { supportive care }\end{array}$ & Good \\
\hline Grunfeld et al. [16] & 1999 & UK & $\begin{array}{l}\text { Breast cancer survivors } n=148 \\
\text { Two district general hospitals }\end{array}$ & $\begin{array}{l}\text { Two-tailed } t \text {-test and } \\
\text { chi-square }\end{array}$ & $\begin{array}{l}\text { Record of visits, average } \\
\text { cost of visits, out-of patient } \\
\text { expenses, waiting times, } \\
\text { lost earnings and lost } \\
\text { earnings of accompanying } \\
\text { person }\end{array}$ & $\begin{array}{l}\text { GP follow-up vs. Hospital } \\
\text { follow-up. Cost-effectiveness } \\
\text { and cost to patient, }\end{array}$ & Average \\
\hline Grunfeld et al. [17] & 2011 & Canada & $\begin{array}{l}\text { Breast cancer survivors } n=408 \\
\text { Nine tertiary cancer centres }\end{array}$ & Two-tailed t-test & $\begin{array}{l}\text { Use of survivorship care plans } \\
\text { (vs. no survivorship care plans) } \\
\text { in primary care physician } \\
\text { led follow-up. Frequency of } \\
\text { visits to oncologists. }\end{array}$ & $\begin{array}{l}\text { Primary care physician led } \\
\text { follow-up }\end{array}$ & Very good \\
\hline Keating et al. [25] & 2006 & USA & $\begin{array}{l}\text { SEER-MEDICARE database Breast } \\
\text { cancer survivors Stage } 1 \text { or } 2 \\
\text { Underwent surgery }>65 \text { years old }\end{array}$ & $\begin{array}{l}\text { Repeated-measures } \\
\text { logistic regression }\end{array}$ & $\begin{array}{l}\text { Mammogram receipt, visits } \\
\text { to primary care physician } \\
\text { medical oncologist, general surgeon, } \\
\text { radiation oncologist and } \\
\text { other specialists, socio-demographics }\end{array}$ & $\begin{array}{l}\text { Factors related to } \\
\text { mammography use }\end{array}$ & Very good \\
\hline Keating et al. [11] & 2007 & USA & $\begin{array}{l}\text { SEER database Breast cancer } \\
\text { survivors }>65 \text { years old } n=37,967 \\
\text { in year } 1 n=30,406 \text { in year } 2 \\
n=23,016 \text { in year } 3\end{array}$ & $\begin{array}{l}\text { Repeated-measures } \\
\text { logistic regression }\end{array}$ & $\begin{array}{l}\text { Receipt of bone scans, tumour } \\
\text { antigen tests (TAT), Chest x-rays } \\
\text { and other abdominal/chest imaging, } \\
\text { frequency of visits to physicians } \\
\text { and socio-demographics }\end{array}$ & $\begin{array}{l}\text { Receipt of a number of } \\
\text { surveillance procedures } \\
\text { and visits to physicians } \\
\text { over time }\end{array}$ & Very good \\
\hline Khan et al. [38] & 2010 & UK & $\begin{array}{l}\text { GPRD database Breast cancer } \\
\text { survivors } N=18,612 \text { Colorectal } \\
\text { cancer survivors } N=5,764 \\
\text { Prostate cancer survivors } \\
N=4,868>30 \text { years old } \\
5 \text { years post-diagnosis } \\
\text { Controls } N=116,418\end{array}$ & Multivariate regression & $\begin{array}{l}\text { Socio-demographics, use of primary } \\
\text { care, frequency of visits }\end{array}$ & $\begin{array}{l}\text { Primary care } \\
\text { consultations }\end{array}$ & Very good \\
\hline
\end{tabular}


Table 1 Study Characteristics (Continued)

\begin{tabular}{|c|c|c|c|c|c|c|c|}
\hline $\begin{array}{l}\text { Khan, Watson } \\
\text { and Rose [20] }\end{array}$ & 2011 & UK & $\begin{array}{l}\text { GPRD database Prostate cancer } \\
\text { survivors } N=4,868 \text { Breast cancer } \\
\text { survivors } N=18,612 \\
\text { Colorectal cancer survivors } \\
N=5,764 \text { Controls } \\
N=145,662\end{array}$ & Logistic regression & $\begin{array}{l}\text { Co-morbidities, screening (PSA, } \\
\text { cervical, mammogram), receipt of } \\
\text { preventative procedures and socio- } \\
\text { demographics }\end{array}$ & $\begin{array}{l}\text { Receipt of screening and } \\
\text { preventative care }\end{array}$ & Very good \\
\hline Knopf et al. [37] & 2001 & USA & $\begin{array}{l}\text { SEER database Colorectal } \\
\text { cancer survivors }>65 \text { years } \\
\text { old } n=52,283\end{array}$ & $\begin{array}{l}\text { Kaplan-Meier survival } \\
\text { analysis }\end{array}$ & $\begin{array}{l}\text { Receipt of colonoscopy, sigmoidoscopy, } \\
\text { endoscopy and barium enema, } \\
\text { age, tumour stage at diagnosis } \\
\text { and year of diagnosis }\end{array}$ & $\begin{array}{l}\text { Receipt of bowel } \\
\text { surveillance } \\
\text { procedures }\end{array}$ & Very Gooc \\
\hline Mahboubi et al. [15] & 2007 & France & $\begin{array}{l}\text { Colorectal cancer survivors } \\
<65 \text { years old } N=389\end{array}$ & Logistic regression & $\begin{array}{l}\text { Co-morbidities, chest radiograph, } \\
\text { abdominal ultrasound, colonoscopy, } \\
\text { CT, TAT, blood tests and reason } \\
\text { for testing (routine or symptomatic) }\end{array}$ & $\begin{array}{l}\text { Characteristics } \\
\text { associated } \\
\text { with visits } \\
\text { to GPs }\end{array}$ & Very good \\
\hline Mandelblatt et al. [13] & 2006 & USA & $\begin{array}{l}\text { Breast cancer survivors } n=418 \\
\text { Stage } 1 \text { and } 2\end{array}$ & $\begin{array}{l}\text { Multivariate linear } \\
\text { regression }\end{array}$ & $\begin{array}{l}\text { Calendar diary of health service use, } \\
\text { socio-demographics, cancer treatment } \\
\text { information, co-morbidities and } \\
\text { psychological status survey }\end{array}$ & $\begin{array}{l}\text { Patterns and } \\
\text { determinants } \\
\text { of health } \\
\text { service use }\end{array}$ & Very good \\
\hline Mayer et al. [35] & 2007 & USA & $\begin{array}{l}\mathrm{NCl} 2003 \text { HINTS }^{5} \mathrm{n}=619 \\
\text { Breast cancer survivors } n=119 \\
\text { Prostate cancer survivors } \\
n=62 \text { Colorectal cancer survivors } \\
n=49 \text { Others } n=389\end{array}$ & Logistic regression & $\begin{array}{l}\text { Based on the health belief } \\
\text { model (HBM), }{ }^{6} \text { cancer communication, } \\
\text { cancer history, general cancer } \\
\text { knowledge, cancer risk and screening, } \\
\text { health status and demographics. }\end{array}$ & $\begin{array}{l}\text { Screening } \\
\text { practices and } \\
\text { beliefs }\end{array}$ & Very good \\
\hline $\begin{array}{l}\text { McBean, Yu } \\
\text { and Virnig [39] }\end{array}$ & 2008 & USA & $\begin{array}{l}\text { SEER database: Uterine cancer } \\
\text { survivors }>65 \text { years old } \\
n=14,575 \text { Controls } n=58,420\end{array}$ & $\begin{array}{l}\text { Multivariate logistic } \\
\text { regression Generalised } \\
\text { equation modelling }\end{array}$ & $\begin{array}{l}\text { Receipt of flu vaccine, bone } \\
\text { densitometry, colorectal } \\
\text { screening and mammogram } \\
\text { no. of physician services and } \\
\text { socio-demographics }\end{array}$ & $\begin{array}{l}\text { Use of preventive } \\
\text { services and } \\
\text { frequency of } \\
\text { physician visits }\end{array}$ & Very good \\
\hline $\begin{array}{l}\text { Mols, Helfenrath } \\
\text { and van de Poll- } \\
\text { Fanse [14] }\end{array}$ & $2007^{a}$ & Netherlands & $\begin{array}{l}\text { Endometrial cancer Prostate } \\
\text { cancer Non-Hodgkin's } \\
\text { lymphoma survivors } \\
n=1,112\end{array}$ & $\begin{array}{l}\text { Linear regression } \\
\text { Multivariate linear } \\
\text { regression }\end{array}$ & $\begin{array}{l}\text { SF-36, self-reported } \\
\text { health service use, frequency } \\
\text { of visits, co-morbidities } \\
\text { and socio-demographics }\end{array}$ & $\begin{array}{l}\text { Patterns of } \\
\text { physician use }\end{array}$ & Very good \\
\hline $\begin{array}{l}\text { Mols, Coebergh } \\
\text { and van de Poll- } \\
\text { Fanse [22] }\end{array}$ & $2007^{b}$ & Netherlands & $\begin{array}{l}\text { Endometrial cancer Prostate } \\
\text { cancer, Hodgkin's and } \\
\text { non-Hodgkin's lymphoma } \\
\text { survivors } n=1,231\end{array}$ & $\begin{array}{l}\text { Chi-square and multivariate } \\
\text { logistic regression }\end{array}$ & $\begin{array}{l}\text { Co-morbidity, socio-demographics, } \\
\text { use of medical specialist, general } \\
\text { practitioner, additional services } \\
\text { (physiotherapist. and psychologist) }\end{array}$ & $\begin{array}{l}\text { Frequency of } \\
\text { physician use }\end{array}$ & Very good \\
\hline
\end{tabular}

2003 HINTS $^{5} n=619$ Breast cancer survivors $n=119$ Prostate cancer survivors

Multivariate logistic equation modelling

inear regression Multivariate linear Chi-square and multivariate Co-morbidity, socio-demographics, (use of medical specialist, genera physiotherapist and psycho scale) 
Table 1 Study Characteristics (Continued)

\begin{tabular}{|c|c|c|c|c|c|c|c|}
\hline Peuckmann et al. [12] & 2009 & Denmark & $\begin{array}{l}\text { Breast cancer survivors } n=1,316 \\
\text { Controls } n=4,865\end{array}$ & $\begin{array}{l}\text { Risk ratios and multiple } \\
\text { logistic regression analysis }\end{array}$ & $\begin{array}{l}\text { Frequency of physical visits, } \\
\text { socio-demographics, } \\
\text { physical activity and } \\
\text { BMI. HR-QOL (SF-36) and } \\
\text { chronic pain }\end{array}$ & $\begin{array}{l}\text { Frequency and } \\
\text { determinants of health } \\
\text { service use }\end{array}$ & Very good \\
\hline $\begin{array}{l}\text { Schapira, McAuliffe } \\
\text { and Nattinger [32] }\end{array}$ & 2000 & USA & $\begin{array}{l}\text { SEER database Breast cancer } \\
\text { survivors }>65 \text { years old } \\
\mathrm{n}=3,885\end{array}$ & Logistic model & $\begin{array}{l}\text { Receipt of mammogram, } \\
\text { co-morbidity, socio-economic } \\
\text { status (SES) and preventive } \\
\text { treatment received }\end{array}$ & $\begin{array}{l}\text { Receipt of Mammogram } \\
\text { over two year period }\end{array}$ & Good \\
\hline Schootman et al. [44] & 2008 & USA & $\begin{array}{l}\text { SEER database Breast cancer } \\
\text { survivors }>65 \text { years old } \\
n=47,643\end{array}$ & $\begin{array}{l}\text { Restricted iterative } \\
\text { generalised least squares } \\
\text { and first-order marginal } \\
\text { quasi-likelihood } \\
\text { estimation analysis }\end{array}$ & $\begin{array}{l}\text { Frequency of Ambulatory- } \\
\text { Care-Sensitive Hospitalizations } \\
(\text { ACSH) })^{7} \text { SES, co-morbidity, } \\
\text { demographics, availability of } \\
\text { medical care, visits to primary } \\
\text { care physician and oncologists }\end{array}$ & $\begin{array}{l}\text { Frequency of } \\
\text { Ambulatory-Care- } \\
\text { Sensitive } \\
\text { Hospitalizations }\end{array}$ & Very good \\
\hline $\begin{array}{l}\text { Simpson, Carlson } \\
\text { and Trew [18] }\end{array}$ & 2001 & USA & $\begin{array}{l}\text { Breast cancer survivors } \\
\text { Time point } 1 \mathrm{n}=46 \text { Time } \\
\text { point } 4 \mathrm{n}=30 \text { Controls Time } \\
\text { point } 1 \mathrm{n}=43 \text { Time point } 4 \\
\mathrm{n}=25\end{array}$ & ANOVA & $\begin{array}{l}\text { Average cost of care, no. of } \\
\text { cancer centre visits and a } \\
\text { number of psychological } \\
\text { distress indicators including BDI, } \\
\text { POMS and Mental adjustment } \\
\text { to cancer scale }\end{array}$ & $\begin{array}{l}\text { Billing of Health } \\
\text { care as a proxy to } \\
\text { use. Visits to } \\
\text { cancer centre } \\
\text { Correlation of } \\
\text { billing to distress. }\end{array}$ & Good \\
\hline Snyder et al. [9] & $2008^{a}$ & USA & $\begin{array}{l}\text { SEER database Colorectal } \\
\text { cancer survivors }>65 \text { years old } \\
n=1,541\end{array}$ & $\begin{array}{l}\text { Poisson regression } \\
\text { and logistic regression }\end{array}$ & $\begin{array}{l}\text { Clinical and socio-demographic } \\
\text { characteristics, visits to primary } \\
\text { care physician, oncologist or } \\
\text { other physicians. Receipt of } \\
\text { influenza vaccine, cholesterol } \\
\text { screening, mammogram, } \\
\text { cervical screening } \\
\text { and bone densitometry }\end{array}$ & $\begin{array}{l}\text { Frequency of } \\
\text { physician visits } \\
\text { and receipt } \\
\text { of preventive care }\end{array}$ & Very good \\
\hline Snyder et al. [10] & $2008^{b}$ & USA & $\begin{array}{l}\text { SEER database Colorectal } \\
\text { cancer survivors }>65 \text { years old } \\
n=20,068\end{array}$ & $\begin{array}{l}\text { Poisson regression } \\
\text { and logistic regression } \\
\text { analysis }\end{array}$ & $\begin{array}{l}\text { Co-morbidities, socio-demographics, } \\
\text { visits to primary care physician, } \\
\text { oncologist and other physicians, } \\
\text { receipt of influenza vaccine, } \\
\text { cholesterol screening, mammogram, } \\
\text { and bone densitometry }\end{array}$ & $\begin{array}{l}\text { Visits to physicians } \\
\text { and receipt of } \\
\text { preventive care }\end{array}$ & Good \\
\hline Snyder et al. [24] & $2009^{a}$ & USA & $\begin{array}{l}\text { SEER database Breast cancer } \\
\text { survivors }>65 \text { years old } n=23,73 \\
\text { Controls } n=23,731\end{array}$ & $\begin{array}{l}\text { Poisson regression } \\
\text { and logistic regression } \\
\text { analysis }\end{array}$ & $\begin{array}{l}\text { Use of physician and } \\
\text { oncology services, receipt } \\
\text { of } 5 \text { preventive care services } \\
\text { and socio-demographics. }\end{array}$ & $\begin{array}{l}\text { Visits to physicians } \\
\text { and oncologists } \\
\text { and preventive } \\
\text { medicine }\end{array}$ & Good \\
\hline Snyder et al. [26] & $2009^{b}$ & USA & $\begin{array}{l}\text { SEER database Breast cancer } \\
\text { survivors }>65 \text { years old Stages } 1-3 \\
n=1,961 \text { Controls } n=1,961\end{array}$ & $\begin{array}{l}\text { Poisson regression } \\
\text { and logistic regression } \\
\text { analysis }\end{array}$ & $\begin{array}{l}\text { Co-morbidities, clinical } \\
\text { and demographic } \\
\text { characteristics, visits to } \\
\text { primary care physician, } \\
\text { oncologists and other } \\
\text { physicians }\end{array}$ & $\begin{array}{l}\text { Frequency of } \\
\text { visits to } \\
\text { physicians }\end{array}$ & Good \\
\hline
\end{tabular}




\section{Table 1 Study Characteristics (Continued)}

Van de Poll-

Fanse et al. [21]

2006 Netherlands Breast

$$
n=183
$$

Yu, McBean

and Virnig $[40]$
2007 USA
Logistic regression

Co-morbidities, spontaneously

reported problems, use of GP, medica

specialist and physiotherapist,

health status and psychological

well-being

Socio-demographic

characteristics, co-morbidities,

receipt of mammogram,

visits to primary care physician,

Gynaecologists only, oncologist

and othe

${ }^{1}$ Usual source of care refers to whether an individual receives care from the same physician or different physicians; ${ }^{2}$ Medicare is a government-funded medical care plan in USA, whereby individuals aged 65 and over that covers medical expenses such as doctor's visits, hospital stays, drugs and other treatment; ${ }^{3} \mathrm{CEA}$ testing is used as a tumour marker for particular cancers, such as colorectal; ${ }^{4} \mathrm{HMO}$ s provide their members with medical services for a fixed fee; ${ }^{5} \mathrm{NCl}$ HINTS is the Health Information National Trends Survey, which collects nationally represented information on how the American public find and use information on cancer; ${ }^{6}$ Developed by Hochbaum (1958) is an explanatory and predictive model of health behaviours and includes attitudes and beliefs of an individual; ${ }^{7} \mathrm{ACSH}$ are hospitalizations which could have been prevented if primary care services had been initially accessed by the individual. 


\section{Table 2 Study results}

\section{Author}

Andersen and

\section{Outcome}

Predisposing characteristics

Urban [36]

\section{Andrykowski and Mental health service use \\ Burris [45]}

Boehmer et al. [34] Follow-up cancer surveillance

Cooper et al. [29]

Follow-up cancer surveillance

Cooper and

Payes [28]

Follow-up cancer surveillance

Older CSs less likely than younger

CSs to receive screening within

3 years of diagnosis. Female CSs

were more likely than male CSs

to receive screening within 3 years of diagnosis. White CSs were more likely than black CSs to receive screening.

Cooper, Kou and Follow-up cancer surveillance Reynolds [31]

Doubeni et al. [27] Primary care use Follow-up cancer surveillance

Older CSs less likely than younger CSs to receive follow-up which adheres to professional guidelines. White CSs more likely than Black CSs to receive follow-up which adheres to professional guidelines.

Younger CSs were more likely to receive a mammography compared to older CSs. White CSs were more likely to receive a mammography compared to black CSs.

Earle et al. [23]
Primary care use Preventative care Older CSs were less likely to receive preventative care compared to younger CSs. Black CSs were less likely to receive preventative care compared to white CSs CSs with lower SES were less likely to receive preventative care compared

\section{Enabling characteristics}

Previous diagnosis via

this method. Physician recommendation

Rural are less likely to have mental health services within 30 mile radius

A greater number of outpatient visits.

Geographical variation in receipt.

Visits to a primary care physician.

Visits to a primary care physician and an oncology specialist.

\section{Need characteristics}

$70 \%$ received mammography in first year. $72 \%$

received mammography in two years.

$18 \%$ of non-rural and $8 \%$ of rural CSs utilised psychologist services.

CSs with a co-morbidity were less likely than CS without a co-morbidity to receive colonoscopy or sigmoidoscopy in first year of survivorship.

Increase in receipt of surveillance procedures over time. Over a 3 year period: $58 \%$ of CSs received on average 28 colonoscopies:

$19 \%$ received on average 2.0 colonoscopies.

Receipt of colonoscopy increased over time.

No difference in receipt of FOBT or colonoscopy between CSs and controls.

CSs with a comorbidity were more likely than CSs without a co-morbidity to receive CEA testing. CSs with later stage and undifferentiated tumour were more likely to exceed guidelines. Decrease over time in receipt of barium enema and sigmoidoscopy.

Visits to a family physician increased from $55-71 \%$ over a 5 year period. CSs with co-morbidities were less likely than CSS without co-morbidities to receive a mammography.

$52 \%$ of CSs followed up by both an oncology specialist and primary care physician. $41 \%$ of CSs followed up by primary care physician only. $4 \%$ of CSs followed up by oncology specialist only. CSs with a co-morbidity were more likely to receive preventative care compared to CSs 
Earle and Neville [19] Primary care use Preventative care Non-white CSs were less likely than

\section{Earle, Neville and} Fletcher [43]

Ellison et al. [33]

Follow-up cancer surveillance

Gray et al. [41]

Mental health service use

Gray et al. [42]

Mental health service use

Grunfeld et al. [16]

Grunfeld et al. [17]

Primary care use

Keating et al. [25]
Primary care use Follow-up cancer surveillance white CSs to receive preventative care. Older CSs compared to younger CSs were less likely to receive preventative care.

Younger breast CSs ( $>65$ years old) were most likely to use mental health services.

White CSs were more likely to receive post-treatment surveillance compared to black cancer survivors.

Younger CSs were more likely to use mental health services than older CSs. CSs who were employed were more ikely to receive mental health services than CSs who were unemployed. CSs who were students were more likely to receive mental health services than

CSs who were not students.

Younger CSs were more likely to use mental health services compared to older survivors.

No visits to primary care physician or oncology specialist led to less

preventative care receipt.

CSs who had additional health insurance were more likely to use mental health services than CSs who did not have additional insurance.

CSs with additional health insurance, higher income and higher education were more likely to use mental health services compared to CSs without additional health insurance, with lower income and education.

A small proportion of CSs followed up by primary care physician made contact with an oncologist in a 12 month period.

Younger and white CSs were more likely to receive a mammogram than CSs who were older and black.
Visits to oncology specialists led to a greater likelihood in the receipt of mammogram by CSS. without a co-morbidity. CSs received more preventative care compared to controls.

CSs compared to general population were more likely to visit a primary care physician. $50 \%$ of CSs visited oncology specialist and other physicians. $8 \%$ of CSs visited oncology specialist only. CSs with a co-morbidity were less likely to receive lipid testing than CSs without a co-morbidity. CSs were less likely than controls to receive lipid or cholesterol testing.

CSs compared to controls were more likely to report anxiety and sleep disorders and have greater use of mental health services $18 \%$ of CSs made at least 2 or 3 visits to a psychologist. Breast cancer survivors had greatest level of use.

Use of colorectal surveillance test increased over time for colorectal CSs.

Younger CSs, with additional health insurance and a higher level of education expressed a need for services that they were not receiving. $31 \%$ CSs made at least one visit to a mental health professional, $5 \%$ to a psychologist and $4 \%$ were to a psychiatrist. 0-11\% of CSs used social services, dieticians, physiotherapists and other health care providers.

CSs led by hospital follow-up had lower health service use compared to CSs led by primary care physician follow-up.

Visits to primary care physicians increased over time, whereas visits to oncology specialists decreased over time. A recent diagnosis, a 
Khan, Watson

and Rose [20]

Knopf et al. [37]

Lafata et al. [30]

Mahboubi et al. [15] Primary care use Follow-up cancer surveillance

Mandelblatt et al. [13] Primary care use Hospital care Follow-up cancer surveillance te CSs were more likely to utilise

health services than black CSs.

Older CSs were less likely than younger CSs to receive follow-up screening within 5 years of treatment with curative intent. White CSs were more likely to receive follow-up screening than black CSs.

CSs living in specific geographic areas.

$21 \%$ of all colorectal surveillance procedures within 3 years of curative surgery were delivered by a primary care physician and $41 \%$ by a gastroenterologist or oncology specialist. risk of developing cancer compared to the general population. likelihood of screening. second cancer, large tumour and no radiotherapy receipt led to a greater likelihood of

mammography receipt

The role of care provided by both primary care physicians and oncology specialists decreased over a three year period. Annual follow-up was provided to $51 \%$ of breast CSs by primary care physicians and $27 \%$ of CSs by oncology specialists.

Receipt of mammography decreased over time. CSs compared to the general population had similar rates of cholesterol testing and blood pressure monitoring. Colorectal CSs were more likely to receive PSA testing. Breast CSs were less likely than the general population to receive preventative care with the exception of bone densitometry.

Visits to primary care physician increased over time by CSs. CSs compared to the general population were more likely to visit their primary care physician.

Receipt of a number of colorectal cancer surveillance procedures increased over time for colorectal CSs following treatment.

Receipt of colonoscopy and CEA and metastatic disease testing increased over time.

ncreased visits to primary care physicians over time.

CSs with a co-morbidity, self-reported poor functioning and high depression scores had greater use and cost of health services. Within the first year of survivorship an average of 14 visits per CS was made to a medical provider. An average of 3 visits to a physiotherapist/ occupational therapist per CS was made. $62 \%$ of CSs received a mammography.

Physician recommendation increased Greater receipt of screening among CSs compared to general population. 
Table 2 Study results (Continued)

McBean, Yu and Preventative care

Virnig [39]

Mols, Helfenrath

and van de Poll-

Fanse [14]

Mols, Coebergh

and van de Poll-

Fanse [22]

Oleske et al. [47]

Peuckmann et al. [12] Primary care use

Schapira, McAuliffe and Nattinger [32]

Follow-up cancer surveillance

Schootman et al. [44] Hospital care

Simpson, Carlson

Primary care

and Trew [18]

Snyder et al. [9]

Primary care use Preventative care

Primary care use Mental health service use
Older and black CSs were less likely to receive preventative care compared to younger and white CSs.

CSs diagnosed between 10 and 15 years previously, who were single or divorced were less likely to utilise health services compared to CSs diagnosed at different time-points and CSs with partners.

Older CSs ( $<75$ years old) were most likely to visit their primary care physician within 3 years of treatment.

Older, divorced or widowed CSs were more likely to be an inpatient than CSS

who were younger, not divorced and not widowed. CSs who were not black or white were less likely to be an inpatient than CSs who were black or white.

ounger, female colorectal CSs were more likely to receive care form both a primary care physician and oncology specialis
Uterine CSs most likely to receive

mammography if seen by a

ive colorectal or

gynaecologist or an oncology
CSs most likely to receive bone

densitometry and influenza vaccination

if seen by a primary care physician.

Receipt of each test most likely if at

least 5 visits to a physician and no

overnight hospital stays.

Higher education enabled use of mental health services.

CSs living in an impoverished area were more likely to have an overnight stay in hospital compared to CSs living in more affluent areas. CSs who had visited their physician at least once were less likely to have an overnight stay than CSs who did not visit their physician.

Participation in psychotherapy intervention led to a reduction in health service use by CSs.

CSs who lived in an urban area compared to CSs who lived in rural area were more likely to
CSs had similar use of primary care physician compared to general population. 0-11 utilised social services, dieticians and

CSs with a co-morbidity were twice as likely to utilise primary care physician services than CSs without a co-morbidity. Endometrial CSs had greater use of health services than the general population. 1-10\% of CSs utilised psychologist services.

$25 \%$ of CSs had at least one overnight hospital stay. Experiencing menopausal symptoms and high CES-D scores led to more inpatient stays.

CSs had similar primary care physician use compared to the general population. Breast CS had greater use of allied health professionals than the general population.

CSs with a co-morbidity were less likely than CS without a co-morbidity to receive a mammography. $23 \%$ of CSs received a macmography in the first 2 years following treatment.

$13 \%$ of CSs had at least one overnight hospital stay. CSs with at least one co-morbidity were more likely to have an overnight stay compared to CSs without a co-morbidity.

CSs had increased visits over time to primary care physician. CSs had decreased visits to oncology specialists over time. Receipt of physiotherapists. 
Table 2 Study results (Continued)

compared to older, male CSs. Older CSs less likely to receive cholesterol testing, cervical examination and bone densitometry than younger CS

Primary care use Preventative care

Snyder et al. [24]

Primary care use Follow-up

cancer surveillance Preventative

care

Primary care use

Preventative care

Van de Poll-

Fanse et al. [21]

Yu, McBean

and Virnig [40]
Primary care use

Follow-up cancer surveillance
Older CSs (>85 years old) were more likely to receive care from a primary care physician compared to CSs aged $<75$ years old. Black CSs were more likely to receive care from physicians other than a primary care physician. Black CSs compared to white CSs were less ikely to receive care from a primary care physician. Non-white CSs were less likely to receive influenza vaccination than white CSs. Older CSs less likely to receive cholesterol testing and bone densitometry but were more likely to receive influenza vaccination more likely to rece
Breast CSs were most likely to receive preventative care if visits were made to an oncology specialist and a primary care physician.

Younger CSs were more likely to visit an oncology specialist compared to older CSs.

Older CSs were less likely to receive mammography compared to younger CSs.

CSs with state health insurance were receive mammography, cervica smear and influenza vaccination. Most likely to receive preventative care if followed-up by both primary care physician and oncology specialist. CSs living in rural areas were less likely to receive mammography compared to CSs living in urban areas.

Most likely to receive preventative care if followed-up by both primary care physician and oncology specialist. mammography and cervical screening decreased over time. Bone densitometry remained low. Rates of influenza vaccination fluctuated over time. CSs with a co-morbidity were less likely to receive cervical screening and bone densitometry, but greater receipt of influenza vaccination, cholesterol testing than CSs without a co-morbidity.

CSs had increased visits over time to other physicians. CSs with a co-morbidity were less likely to receive cervical screening and bone densitometry, but greater receipt of influenza vaccination, cholesterol testing and mammography than CSs without a co-morbidity.

Majority of CSs followed up by both oncology specialist and primary care physician over time. Increased visits to oncology specialist over time. Decreased visits to primary care physician over time. Breast CSs had greater use of mammography compared to the general population. Breast CSs received less preventative care than the general population. CSs more likely o receive preventative care if general population has a co-morbidity.

Increased visits to primary care physician over time. Decreased visits to oncology specialist over time. Breast CSs received less preventative care than the general population.

Breast CSs had similar primary care physician use as the general population.

less to receive a mammography

compared to CSs with alternative health insurance. CSs living in a rura area were less likely to receive

mammography compared to CSs

living in an urban area. Care from a

gynaecologist rather than a primary

care physician led to greater

receipt of mammography. 
colorectal CSs were consistently less likely to receive surveillance procedures within 3 years of diagnosis [28], 5 years of diagnosis and treatment [29,30], and they were also less likely to receive follow-up surveillance in adherence to government follow-up guidelines [31]. At the time of the study a number of guidelines for colorectal cancer follow-up care had been developed but none had been widely implemented. Therefore, the authors amalgamated these guidelines to create a minimum number of service and procedure receipt recommendations. These recommendations included: at least two visits to a physician per year; the receipt of at least two Carcino-Embryonic Antigen (CEA) tests within each of the first two years of survivorship; and the receipt of at least one colonoscopy within the first three years of survivorship. Excess of government guidelines included receiving the minimum level of care in addition to the receipt of at least one CT scan and/or at least one PET scan [31]. Older breast CSs were also less likely to receive mammograms compared to their younger counterparts [25,27,32].

The majority of the evidence regarding ethnicity and uptake of follow-up surveillance found that white CSs were more likely to receive follow-up screening $[25,27,28,30,32,33]$ and to adhere to the guidelines specified above [31] than CSs of other ethnicities. A study based at a 'safety-net hospital' which provided care to underserved populations such as ethnic minorities found that black colorectal CSs were more likely to receive follow-up colonoscopies within 3-years of curative resection than CSs of other ethnicities [34]. The extent to which gender predisposes follow-up cancer surveillance is unclear. Within the first three years of diagnosis, females were more likely to utilise colorectal screening compared to male colorectal CSs, [28] but were less likely than males to receive either colonoscopy or sigmoidoscopy within 1 and 3 years of treatment [34]. Colorectal CSs perceived a greater absolute and comparative risk for developing cancer leading to greater receipt of screening compared to non-cancer controls [35].

\section{Enabling characteristics}

Factors which enabled receipt of follow-up surveillance included visits to specific health-care providers, frequency of health-care contact, area of residence, physician recommendation of test and previous cancer diagnosis detected via screening procedure. Variations in colorectal cancer surveillance uptake by French colorectal CSs were dependent on type of physician; $21 \%$ of all colorectal surveillance procedures within 3 years of curative surgery were delivered by a primary care physician and $41 \%$ by a gastroenterologist or an oncologist [15]. An increased number of outpatient visits led to a greater likelihood of receiving colonoscopy or sigmoidoscopy within 3 years of treatment for colorectal CSs [34]. A significant geographical variation in receipt of surveillance procedures was also observed for colorectal CSs [29]. An explanation for this variation given by the authors was the influence of local practice on testing. Moreover, a physician recommendation of follow-up procedures increased the likelihood of procedure uptake for breast CSs and prostate CSs $[35,36]$. Receiving a previous breast cancer diagnosis detected by a mammogram was significantly and positively associated with subsequent receipt of mammogram in the survivorship period [36].

\section{Need characteristics}

Co-morbid illnesses, cancer stage and treatment history were significant need characteristics associated with receipt of follow-up surveillance. Presence of a co-morbid illness led to a lower likelihood of receiving follow-up surveillance. Colorectal CSs with a co-morbidity were less likely to receive colonoscopy and sigmoidoscopy than CSs without a co-morbidity in the first year of survivorship and were less likely to receive CEA testing to the standard recommended by US follow-up guidelines which included receiving at least two CEA tests per year $[29,31]$. This finding is further supported by the breast cancer survivorship literature. Breast CSs with comorbidities compared to CSs without co-morbidities were less likely to receive a mammogram [25,27,32]. Colorectal CSs with later stage and an undifferentiated cancer were more likely to exceed recommended guidelines which included receipt of at least one CT and/or PET scan, in addition to minimum recommendations [31]. Further factors associated with mammography receipt for breast CSs were a more recent diagnosis, a secondary cancer, a large tumour and no history of adjuvant radiotherapy [11]. Comparisons of surveillance procedure receipt between CSs and non-cancer controls were largely consistent. Breast CSs had significantly greater use of mammogram compared to controls when adjustments were made for age, race and access to health-care [26,35]. A similar result was found for PSA testing among prostate CSs [35]. However, one study found that having a cancer history did not lead to differential receipt of Faecal Occult Blood Test (FOBT) or colonoscopy compared to the general population [28]. Rates of follow-up surveillance receipt varied across studies and cancer sites, overall rates of uptake were low to moderate. Eleven percent of colorectal CSs received at least one surveillance procedure each year [28]. Over a three year period, $58 \%$ of colorectal CSs in the USA received on average 2.8 colonoscopies, a lower percentage (19\%) received on average 2.0 sigmoidoscopies and there was an observed decrease in the receipt of barium enema and sigmoidoscopy [29,31]. In contrast to this finding some studies reported an increase over time in the receipt of a number of colorectal cancer surveillance 
procedures following treatment specifically colonoscopy, CEA testing and metastatic disease testing [28-31,37].

For breast CSs the receipt of mammography decreased over time, with the exception of one study. Sixty-two percent of breast CSs received a mammography in both the first and second years of survivorship whereas $23 \%$ of breast CSs received a mammogram in either year of the first two years of survivorship [13,32]. A further two studies reported a decrease over time in mammogram receipt $[27,38]$ whereas another study reported an increase over a two year period [36]. A few studies assessed the level of surveillance receipt in comparison to government-recommended guidelines. The majority of CSs did not meet recommended levels of surveillance receipt; in one study $17 \%$ of colorectal CSs met the guidelines, $23 \%$ exceeded the guidelines and $60 \%$ failed to meet the guidelines. Guidelines have been described above [31]. In the first year of survivorship between 11$59 \%$ of breast CSs received surveillance procedures such as a chest $\mathrm{x}$-ray which were not recommended by American Society of Clinical Oncology (ASCO) guidelines [11].

\section{Preventive care \\ Predisposing characteristics}

Significant predisposing variables for receipt of preventive care included ethnicity and age. White CSs were consistently more likely to receive preventive care than non-white CSs. Colorectal CSs who were non-white were less likely to receive preventive care, particularly influenza vaccination $[9,19]$ than white CSs. Furthermore, white breast and uterine CSs were more likely to receive preventive care compared to black CSs [23,39]. The evidence was consistent regarding age and receipt of preventive care, whereby older CSs were less likely to receive preventive care (with the exception of influenza vaccination) than their younger counterparts. Older colorectal CSs were less likely to receive preventive care including cholesterol testing, cervical examination, bone densitometry and mammography, $[9,10,19,40]$ but were more likely to receive influenza vaccinations than younger cancer survivors [10]. Older breast and uterine CSs were less likely to receive preventive care compared to younger CSs [23,39]. A UK-based study found that colorectal, breast and prostate CSs over the age of 65 were more likely to receive influenza vaccination than younger CSs [38].

\section{Enabling characteristics}

Enabling characteristics associated with the receipt of preventive care included visits made to specific physicians, frequency of health-care contact, area of residence, socio-economic status, overnight hospitalisations and health insurance. Visits to more than one type of health-care provider (i.e. primary care physician and oncologist) were more likely to facilitate receipt of preventive care. This finding was consistent for both colorectal and breast CSs respectively [9,10,23,24,26]. Visits made by colorectal CSs to either a primary care physician or an oncologist facilitated receipt of preventive care, but not at the same level as visits made to both health-care providers; whereas CSs who did not visit either health care provider received the lowest levels of preventive care receipt [19]. Moreover, general preventive care (i.e. bone densitometry) was more likely to be delivered by a primary care physician than any other type of physician. Oncologists and gynaecologists were more likely to deliver cancer-related preventive care such as mammography to colorectal and uterine CSs respectively $[9,40]$. Moreover, an increasing number of visits to a health-care provider was the strongest predictor for receipt of preventive care for a sample of UK CSs [38]. A study of uterine CSs in the US quantified this amount as 5 or more visits to a physician [39]. Living in an urban area was significantly associated with greater receipt of mammography, influenza vaccination and cervical smear among colorectal CSs $[9,40]$ and general preventive care among breast CSs [23]. One study reported that breast CSs who had lower socio-economic status were less likely to receive preventive care compared to breast CSs with higher socio-economic status [23]. Receipt of preventive health services among uterine CSs who had not been hospitalised was greater compared to CSs who had been hospitalised. Furthermore, colorectal CSs with private health insurance were more likely to receive a mammogram compared to colorectal CSs with government-funded health insurance [39].

\section{Need characteristics}

Colorectal CSs with a co-morbidity were less likely to receive lipid testing, cervical screening and bone densitometry, but were more likely to receive influenza vaccination, cholesterol testing and mammography compared to CSs without a co-morbidity $[9,10,19]$. Conversely, breast CSs with a co-morbidity were more likely to receive overall preventive care than CSs without a comorbidity [23]. Evaluation and Management meetings refer to service contact which is not for the intention of procedures or tests. Survivors with a co-morbidity who attended for Evaluation and Management meetings were more likely to receive a mammography than CSs who did not attend for Evaluation and Management meetings [40]. Rates of preventive care receipt were not consistent between CSs and non-cancer controls. Breast and uterine CSs were more likely than controls to receive preventive care such as colorectal cancer screening [23,39]. An UK-based study found comparative rates of cholesterol testing and blood pressure monitoring between CSs (including prostate and breast cancers) and the 
general population, but a $19 \%$ increased likelihood of PSA testing for colorectal CSs compared to the general population [38]. Comparisons of preventive care receipt between breast CSs and healthy controls demonstrated that CSs were less likely to receive preventive care, particularly lipid and cholesterol testing [19,24,26]. However, they were more likely to receive bone densitometry or general preventive care than non-cancer controls with co-morbidities [24,38]. Colorectal CSs receipt of mammography and cervical screening decreased over time, receipt of bone densitometry remained low, whereas rates of influenza vaccination fluctuated over time [9].

\section{Hospital care including mental health services Predisposing characteristics}

Support was found for age, employment and student status as predisposing characteristics associated with the use of mental health services. Younger age $(<65$ year olds vs. $>65$ year olds) was significantly associated with seeking mental health or supportive care services among breast CSs in two Canadian studies [41,42] and among survivors of breast, lymphoma, colorectal, melanoma and other cancers in one US study [43]. Breast CSs who reported that they were currently employed or a student were more likely to utilise professional supportive care services [41].

Two US studies reported on the patterns of inpatient hospitalisations among breast CSs. Only one of these studies addressed the predisposing characteristics associated with being hospitalised. Ambulatory-Care-Sensitive Hospitalisations or preventable hospitalisations were associated with older age, being widowed or divorced and lower likelihood was associated with being of an ethnicity other than white and black [44].

\section{Enabling characteristics}

Education level, household income, health insurance and residential area were enabling factors associated with the use of mental health services. CSs with a high level of education were more likely to utilise mental health services compared to CSs with a lower level of education; this was supported by a study of endometrial, prostate and lymphoma CSs in the Netherlands [14] and breast CSs in Canada [41,42]. Household income which is strongly associated with educational level was a significant enabling characteristic for mental health service utilisation; both Canadian studies found that higher household income resulted in greater likelihood of using mental health services $[41,42]$. Further results from these two studies found that additional health insurance compared to government-funded insurance was associated with increased mental health service use [41,42]. One US study addressed the impact of urban or rural residence on receipt of mental health services among breast, colorectal and haematological CSs and found no significant difference in service receipt despite rural CSs being less likely to have psychiatric services within 30 miles of their home [45].

Enabling characteristics associated with inpatient hospitalisations included socio-economic status of residential area and previous visits to a physician. CSs from an impoverished area compared to a more affluent area were more likely to experience an Ambulatory-CareSensitive Hospitalisation. However, if CSs had visited a physician recently the risk of being hospitalised was reduced [44].

\section{Need characteristics}

Experiencing a psychological disorder and expressing an explicit need for mental health services was associated with use of mental health or supportive care services. CSs reported a greater need for and use of mental health services compared to the general population without cancer, due to a higher prevalence of anxiety and sleep disorders [43]. Canadian breast CSs were asked if they were in need of, or could not access mental health services; breast CSs who were younger, had additional health insurance or a high level of education, were working or studying were more likely to report an explicit need for services [42]. Rates of mental health service utilisation were low among CSs ranging from $1 \%$ to $18 \%$. Between 1 and $10 \%$ of CSs in the Netherlands utilised psychology services; survivors of lymphoma had the greatest use of psychology services compared to survivors of endometrial and prostate cancers [14]. There were low utilisation rates of both psychiatric and psychology services among Canadian breast CSs (4\% and $5 \%$ respectively) [41]. Eighteen percent of USA CSs made on average 2 or 3 visits to a mental health professional and breast CSs were the highest users of services [43]. Between-study variation in rates may be due to different modes of access to services across health care systems.

Need-related factors associated with inpatient hospitalisations included having at least one co-morbidity, experiencing menopausal symptoms and higher scores on the Centre for Epidemiology Studies-Depression scale (CES-D). Between $13 \%$ and $25 \%$ of breast CSs had at least one overnight hospital stay $[44,46]$.

The use of other health services such as social services or dietetics ranged from 0-11\% of CSs [22,42]. Danish breast CSs had greater utilisation of allied health care professionals than the general population, [12] and US CSs had an average number of 3 visits per survivor to a physiotherapist or an occupational therapist [13].

\section{Discussion}

The results of this review are consonant with the Andersen Behavioural Model of health service utilisation. Younger, 
white and employed or student CSs were more predisposed to access and receive health care. Individuals over 65 years old represent an at-risk group and are encouraged by their health-care provider to receive vaccination annually [47]. According to the results of this review, older CSs were more likely to receive influenza vaccination but not other types of care. This discrepancy between older and younger CSs in terms of receipt of preventive services may be explained partly by physicians making decisions about the utility of preventive care based on the life expectancy of CSs, $[9,10,40]$ - this may also explain the increased risk regarding inpatient hospitalisations among elderly CSs. The role of incentive payments to primary care physicians may play a part in the differential patterns of preventive services utilisation. Ethnicity was examined within US studies only and various explanations relating to economic differences, differences in healthseeking behaviours, preferences for treatment or perceptions of post-treatment cancer surveillance may account for reported ethnic disparities [19,30,33].

Visits to primary care physicians appeared to enable the implementation of care recommendations for CSs. Other facilitating factors which were more pertinent in non-nationalized or universal health-care systems were additional health insurance, a higher education, income and living in an urban, affluent area. Many samples included CSs who had insurance (e.g. Medicare) and this factor may be related to a sense of self-efficacy in terms of seeking information and negotiating the health-care system [42]. Cancer survivors had greater or at least similar frequency of contact with primary care physicians compared to the general population without cancer. Many cancer survivors may experience long-term health problems or further ill-health following treatment which require further care or specialist care. In many health-care systems a primary care physician may act as a gatekeeper for access to specialist services thus accounting for greater frequency of visits among the cancer survivor population.

Needs for care were also related to co-morbidity, later stage or undifferentiated tumour and menopausal or depressive symptoms. Younger, employed or student CSs expressed a need for mental health services. Overall, as CSs survived longer post-diagnosis they used less cancer-oriented care, with the exception of screening.

Although the review amalgamated literature regarding core health services, it excluded some health services such as complementary and alternative medicine due to resource restraints (and their perceived non-mainstream position). Services like complementary and alternative medicine are becoming increasingly important for CSs and require research attention. Limitations of the review include uncertainty about generalisability of findings. There is a need to give consideration to the merits of conducting comparative health care system research (including health service research in non-USA countries), particularly given the differing role of the oncologist between health-care systems and the role of insurance in obtaining access to care in USA studies. Fifteen studies comprised a secondary analysis of the SEER-Medicare database which included individuals over the age of 65 years and excluded individuals covered by other insurance plans or no insurance plan. Moreover, individuals were limited by their insurance plan regarding access to physicians and entitlement to receive particular procedures. For example, there are additional charges for receipt of procedures such as colonoscopy [33]. A further issue for the review was the lack of generalisation of results to US cancer survivors without medical insurance and thus a primary care physician may not be the first point of contact for care for some individuals. The SEER-Medicare database also did not provide information regarding reasons for use of services (i.e. cancerrelated follow-up or for another condition). None of the papers reported the reasons for health service contact and whilst CSs appeared to be using relevant health services, this did not equate to follow-up care. It may not have been appropriate to compare utilisation rates between CSs and 'healthy' individuals from the general population as they may also have chronic illnesses; this is an inherent limitation within the included primary studies. Unfortunately, none of the included studies examined the nature and extent of the coordination of different services provided for CSs and this needs to be empirically tested.

The Andersen Behavioural Model of health service utilisation was used as the structural framework to organise the review. Although it is limited in its scope regarding potentially important behavioural variables, it does take into account the health beliefs of an individual. Health beliefs were not extensively addressed by the studies in the review. Indeed, only one study looked at the perception of risk and only in respect of cancer recurrence. There is a need to give empirical attention to the role of research evidence-based behavioural and 'cognitive-behavioural' constructs in order to improve our understanding preventive procedure receipt and adoption of health promoting behaviours by cancer survivors [48]. Future research efforts to understand health service use by cancer survivors should consider supplementing or expanding the Andersen Behavioural Model to include behavioural and cognitive components (e.g. subjective norms) from models such as the Theory of Planned Behaviour [49].

\section{Conclusions}

The emergence and evaluation of practice guidelines over time may impact on health service utilisation. 
Although plans are currently underway neither the USA nor the UK have well-established guidelines which indicate appropriate contact use or receipt of health services, [50,51]. Currently, it is not clear who should co-ordinate care plans and what they should entail [52]. Overall, personalised care plans and an active role played by physicians were significant enablers in terms of helping match services to the needs of CSs and facilitating co-ordinated care - at least for particular groups of survivors.

\section{Abbreviations}

CS: Cancer survivor; STROBE: STrengthening the Reporting of OBservational studies in Epidemiology; CEA: Carcino-Embryonic Antigen testing; ACSO: American Society of Clinical Oncology; FOBT: Faecal Occult Blood Test; PSA: Prostate Antigen Testing; CES-D: Centre of Epidemiological StudiesDepression scale.

\section{Competing interests}

The authors do not have any financial, professional or personal conflicts to declare that are relevant to this manuscript.

\section{Authors' contributions}

$\mathrm{CT}$ was responsible for implementing the search strategy, screening papers/studies for inclusion and exclusion and drafting the manuscript under MD's supervision. Both authors read and approved the final manuscript.

\section{Acknowledgements}

This work was supported by funding from the Department of Education and Learning (DEL) for a PhD studentship awarded to CT.

\section{Author details}

${ }^{1}$ Cancer Epidemiology \& Health Services Research Group, Centre for Public Health, Queen's University Belfast, Belfast, UK. ${ }^{2}$ UKCRC Centre of Excellence for Public Health, Queen's University Belfast, Belfast, UK.

Received: 24 February 2012 Accepted: 10 September 2012 Published: 13 September 2012

\section{References}

1. Coleman MP, Forman D, Bryant H, Butler J, Rachet B, Maringe C, Nur U, Tracey E, Coory M, Hatcher J, McGahan CE, Turner D, Marrett L, Gjerstorff ML, Johannesen TB, Adolfsson J, Lambe M, Lawrence G, Meechan D, Morris EJ, Middleton R, Steward J, Richards MA: Cancer survival in Australia, Canada, Denmark, Norway, Sweden and the UK, 1995-2007 (the International Cancer Benchmarking Partnership): an analysis of population-based cancer registry data. Lancet 2011, 377:127-38.

2. Santin O, Mills ME, Treanor C, Donnelly M: A comparative analysis of the health and wellbeing of cancer survivors to the general population. Support Care Cancer 2012, 2012, in press.

3. Elliott J, Fallows A, Staetsky L, Smith PWL, Foster CL, Maher EJ, Corner J: The health and well-being of cancer survivors in the UK: findings from a population-based survey. Brit J Cancer 2011, 105(Suppl 1):S11-20.

4. Weinstein MC, Skinner JA: Comparative effectiveness and health care spending- implications for reform. New Engl JMed 2010, 362:460-5.

5. Centre for Reviews and Dissemination: Systematic reviews. University of York: CRD's guidance for undertaking reviews in health care; 2009.

6. Donnelly DW, Gavin AT: Survival of cancer patients in Northern Ireland: 19932004. Queen's University, Belfast: Northern Ireland Cancer Registry; 2007.

7. Gomm R, Needham G, Bullham A: Evaluating Research in Health and Social Care. London: Sage Publications; 2000.

8. Sanderson S, Tatt ID, Higgins JPT: Tools for assessing quality and susceptibility to bias in observational studies in epidemiology: a systematic review and annotated bibliography. Int J Epidemiol 2007, 36:666-76.
9. Snyder CF, Earle CC, Herbert RJ, Neville BA, Blackford AL, Frick KD: Preventive care for colorectal cancer survivors: a 5-year longitudinal study. J Clin Oncol 2008, 26:1073-9.

10. Snyder CF, Earle CC, Herbert RJ, Neville BA, Blackford AL, Frick KD: Trends in follow-up and preventive care for colorectal cancer survivors. J Genl Intern Med 2008, 23:254-9.

11. Keating NL, Landrum MB, Guadagnoli E, Winer EP, Ayanaian JZ: Surveillance testing among survivors of early-stage breast cancer. J Clin Oncol 2007, 25:1074-1081.

12. Peuckmann V, Elkholm $O$, Sjogren $P$, Rasmussen NK, Christiansen $P$, Moller $S$, Groenvold M: Health care utilisation and characteristics of long-term breast cancer survivors: nationwide survey in Denmark. Eur J Cancer 2009, 45:625-33.

13. Mandelblatt JS, Lawrence WF, Cullen J, Stanton AL, Krupnick JL, Kwan L, Ganz PA: Patterns of care in early-stage breast cancer survivors in the first year after cessation of active treatment. J Clin Oncol 2006, 24:77-84.

14. Mols F, Helfenrath KA, Vingerhoets AJ: Increased health care utilization among long-term cancer survivors compared to the average Dutch population: a population-based study. Int J Cancer 2007, 121:871-7.

15. Mahboubi A, Lejeune C, Coriat R, Binquet C, Bouvier A, Béjean S, Bedenne L, Bonithon-Kopp C: Which patients with colorectal cancer are followed up by general practitioners? A population-based study. Eur J Cancer Prev 2007, 16:535-41.

16. Grunfeld E, Gray A, Mant D, Yudkin P, Adewuyi-Dalton R, Coyle D, Cole D, Stewart J, Fitzpatrick R, Vessey M: Follow-up of breast cancer in primary care vs specialist care: results of an economic evaluation. Brit J Cancer 1999, 79:1227-33.

17. Grunfeld E, Julian JA, Pond G, Maunsell E, Coyle D, Folkes A, Joy AA, Provencher L, Rayson D, Rheaume DE, Porter GA, Paszat LF, Pritchard KI, Robidoux A, Smith S, Sussman J, Dent S, Sisler J, Wiernikowski J, Levine MN: Evaluating survivorship care plans: results of a randomized clinical trial of patients with breast cancer. J Clin Oncol 2011, 29:4755-62.

18. Simpson JS, Carlson LE, Trew ME: Effect of group therapy for breast cancer on healthcare utilization. Cancer Pract 2001, 9:19-26.

19. Earle CC, Neville BA: Under use of necessary care among cancer survivors. Cancer 2004, 101:1712-19.

20. Khan NF, Watson E, Rose PW: Primary care consultation behaviours of long-term, adult survivors of cancer in the UK. Brit J Gen Pract 2011, 61:197-9.

21. van de Poll-Fanse LV, Mols F, Vingerhoets AJ, Voogd AC, Roumen RM Coebergh JW: Increased health care utilisation among 10-year breast cancer survivors. Supportive Care Cancer 2006, 14:436-43.

22. Mols F, Coebergh JW, van de Poll-Fanse LV: Health-related quality of life and health care utilisation among older long-term cancer survivors: a population-based study. Euro J Cancer 2007, 43:2211-21.

23. Earle CC, Burnstein HJ, Winer EP, Weeks JC: Quality of non-breast cancer maintenance among elderly breast cancer survivors. J Clin Oncol 2003, 21:1447-51

24. Snyder CF, Frick KD, Kantsiper ME, Peairs KS, Herbert RJ, Blackford AL, Wolff $A C$, Earle CC: Prevention, screening and surveillance care for breast cancer survivors compared with controls: changes from 1998 to 2002. J Clin Oncol 2009, 27:1054-61.

25. Keating NL, Landrum MB, Guadagnoli E, Winer EP, Ayanian JZ: Factors related to underuse of surveillance mammography among breast cancer survivors. J Clin Oncol 2006, 24:85-94.

26. Snyder CF, Frick KD, Kantsiper ME, Peairs KS, Herbert RJ, Blackford AL, Wolff $A C$, Earle CC: Comparing care for breast cancer survivors to non-cancer controls: a five-year longitudinal study. J Gen Intern Med 2009, 24:469-74.

27. Doubeni CA, Field TS, Yood MU, Rolnick SJ, Quessenberry CP, Fouayzi H, Gurwitz JH, Wei F: Patterns and predictors of mammography utilization among breast cancer survivors. Cancer 2006, 106:2482-8.

28. Cooper GS, Payes JD: Temporal trends in colorectal procedure use after colorectal cancer resection. Gastrointest Endosc 2006, 64:933-40.

29. Cooper GS, Yuan Z, Chak A, Rimm AA: Patterns of endoscopic follow-up after surgery for nonmetastatic colorectal cancer. Gastrointest Endosc 2000, 52:33-8.

30. Lafata JE, Johnson CC, Ben-Menachem T, Morlock RJ: Sociodemographic Differences in the receipt of colorectal cancer surveillance care following treatment with curative intent. Med Care 2001, 39:361-72. 
31. Cooper GS, Kou TD, Reynolds HL Jr: Receipt of guideline-recommended follow-up in older colorectal cancer survivors: a population-based analysis. Cancer 2008, 113:2029-37.

32. Schapira MM, McAuliffe TL, Nattinger AB: Underutilization of mammography in older breast cancer survivors. Med Care 2000, 38:281-189.

33. Ellison GL, Warren $J \mathrm{~L}$, Knopf KB, Brown ML: Racial differences in the receipt of bowel surveillance following potentially curative colorectal cancer surgery. Health Serv Res 2003, 2003(38):1887-904.

34. Boehmer U, Harris J, Bowen DJ, Schroy PC III: Surveillance after colorectal cancer diagnosis in a safety net hospital. J Health Care Poor U 2010, 21:1138-51.

35. Mayer DK, Terrin NC, Menon U, Kreps GL, McCance K, Parsons SK, Mooney KH: Screening practices in cancer survivors. J Cancer Surviv 2007, 1:17-26.

36. Andersen MR, Urban N: The use of mammography by survivors of breast cancer. Am J Public Health 1998, 88:1713-15.

37. Knopf KB, Warren JL, Feuer EJ, Brown ML: Bowel surveillance after a diagnosis of colorectal cancer in Medicare beneficiaries. Gastrointest Endosc 2001, 54:563-71.

38. Khan NF, Carpenter L, Watson E, Rose PW: Cancer screening and preventative care among long-term cancer survivors in the United Kingdom. Brit J Cancer 2010, 102:1085-90.

39. McBean AM, YU X, Virnig BA: The use of preventive health services among elderly uterine cancer survivors. Am J Obstet Gynecol 2008, 86:e2.

40. Yu X, McBean M, Virnig BA: Physician visits, patient comorbidities, and mammography use among elderly colorectal cancer survivors. J Cancer Surviv 2007, 1:275-82.

41. Gray RE, Goel V, Fitch MI, Fransenn E, Chart P, Greenberg M, Bakker D, Labrecque M, Holloway E, Godel R, Wray Hampson A: Utilization of professional supportive care services by women with breast cancer. Breast Cancer Res Treat 2000, 64:253-8.

42. Gray RE, Goel V, Fitch MI, Franssen E, Labrecque M: Supportive care provided by physicians and nurses to women with breast cancer: results from a population-based survey. Support Care Cancer 2002, 10:647-52.

43. Earle CC, Neville BA, Fletcher R: Mental health service utilization among long-term cancer survivors. J Cancer Surviv 2007, 1:156-60.

44. Schootman M, Jeffe DB, Lian M, Deshpande AD, Gillianders WE, Aft R, Sumners W: Area-level poverty is associated with greater risk of Ambulatory-care-sensitive hospitalizations. J Am Geriatr Soc 2008, 56:2180-2187

45. Andrykowski MA, Burris JL: Use of formal and informal mental health resources by cancer survivors: differences between rural and nonrural survivors and a preliminary test of the theory of planned behaviour. Psychooncology 2010, 19:1148-55.

46. Oleske DM, Cobleigh MA, Phillips M, Nachman KL: Determination of factors associated with hospitalization in breast cancer survivors. Oncol Nurs Forum 2004, 31:1081-8.

47. Simonsen LT, Reichert A, Viboud C, Blackwelder WC, Taylor RJ, Miller MA: Impact of influenza vaccination on seasonal mortality in the US elderly population. Arch Intern Med 2005, 165:265-72.

48. Findley PA, Sambamoorthi U: Preventive health services and lifestyle practices in cancer survivors: a population health investigation. $J$ Cancer Surviv 2009, 3:43-58.

49. Ajzen I: The theory of planned behavior. Organ Behav Hum 1991 50:179-211.

50. Hewitt M, Greenfield S, Stovall E: From Cancer Patient to Cancer Survivor: Lost in Transition. Washington: The National Academies Press; 2006.

51. Initiative NCS: The National Cancer Survivorship Initiative Vision. London: Westminster; 2010.

52. Lichtenfeld L: Cancer care and survivorship planning: Promises and challenges. J Oncol Pract 2009, 5:116-18.

doi:10.1186/1472-6963-12-316

Cite this article as: Treanor and Donnelly: An international review of the patterns and determinants of health service utilisation by adult cancer survivors. BMC Health Services Research 2012 12:316.

\section{Submit your next manuscript to BioMed Central and take full advantage of:}

- Convenient online submission

- Thorough peer review

- No space constraints or color figure charges

- Immediate publication on acceptance

- Inclusion in PubMed, CAS, Scopus and Google Scholar

- Research which is freely available for redistribution

Submit your manuscript at www.biomedcentral.com/submit 